\title{
Electrochemical Oxidation of Acid Yellow and Acid Violet Dyes Assisted by Transition Metal Modified Kaolin
}

\author{
M.M. Ahmed ${ }^{*}$ \\ Chemistry Department, University College of Girls for Arts, Science and Education, Ain Shams \\ University, Heliopolis, Cairo, Egypt
}

\begin{abstract}
Electrochemical oxidation of some dyes making wastewater assisted by transition metal $(\mathrm{Co}, \mathrm{Cu})$ modified kaolin in an electrolytic cell with graphite plates as electrodes was investigated. $\mathrm{H}_{2} \mathrm{O}_{2}$, produced on the surface of porous graphite cathode reacts with the $(\mathrm{Co}, \mathrm{Cu})$ modified kaolin catalyst to form strong oxidant (hydroxyl radicals $\mathrm{HO}^{*}$ ) that can in turn degrade the pollutants adsorbed on the surface of kaolin. Series of experiments were done to prove the synergetic effect of the combined oxidation system and to find out the optimal operating conditions such as initial solution $\mathrm{pH}$, current density, time of electrolysis, and amount of modified kaolin catalyst. It was found that when the initial $\mathrm{pH}$ was 3 , current density of $40 \mathrm{~mA} / \mathrm{cm}^{2}$, electrolysis time of 40 minutes and catalyst dose of $15 \mathrm{~g} / \mathrm{L}$, the COD (chemical oxygen demand) removal could reach up to about $100 \%$ for the two investigated dyes.
\end{abstract}

Keywords: electrocatalysis, dyes wastewater, transition metals modified kaolin.

\section{Introduction}

Increasingly stringent effluent discharge permit limitations have been put into effect [1]. The textile industry generally has difficulty in meeting wastewater discharge limits, particularly with regard to dissolved solids, ionic salts, $\mathrm{pH}$, COD, colour, and sometimes heavy metals.

The problem of colour in textile dye house effluent and the possible problems associated with the discharge of dyes and dye degradation products are of concern.

Traditional methods for dealing with this kind of wastewater are usually the biological, physical and chemical techniques as well as the various combinations

\footnotetext{
* Corresponding author. E-mail address: drsohairr@hotmail.com
} 
[2]. Many advanced treatments have been studied and electrochemical oxidation has been applied to many kinds of wastewater [3-7].

In electrochemical methods the main reagent is the electron [8] which is a clean reagent. Electrochemical treatment of wastewater offers high removal efficiencies and has lower temperature requirements compared to nonelectrochemical treatment. In addition, it could prevent the production of unwanted side-products and there is no need for addition of chemicals to the treated wastewater.

Many researches [7,8] have demonstrated that the new advanced oxidation technologies, which are based on the in situ formation of $\mathrm{OH}$ radicals, have been successfully applied to the complete mineralization of different kinds of organic compounds. Among them, electrochemical technologies used to treat various wastewaters have been extensively investigated. Research works have been focused on the efficiency in oxidizing various pollutants on different electrodes, improvement of the electrocatalytic activity and electrochemical stability of electrode materials. Till now many works have been done to develop high catalytic activity, long life, etc., including glassy carbon electrode [9], carbon felt [10], Pt/Ti and graphite [11].

Catalytic electrochemical oxidation of wastewater has been extensively studied so far. Most of the degradation processes were conducted in aqueous phase using porous graphite cathode in the presence of $\mathrm{Fe}^{2+}$ ions to form electro-Fenton system. Others like anodic oxidation, also called electrochemical incineration, are using the adsorbed hydroxyl radicals ( $\left.\mathrm{OH}^{*}\right)$ formed on the anode surface to destroy organics. Hydroxyl radicals are very powerful oxidizing agents that react with organics giving dehydrogenated or hydroxylated derivatives until achieving their complete mineralization.

Transition metals modified kaolin as catalyst used in the electro-chemical system is a new and effective approach in many studies when treating the oil produced water and anionic surfactants wastewater [12,13]. Kaolin traditionally used to stabilize heavy metals [14] and catalyze organic reactions [15] was rarely reported to catalyze degradation of wastewater in electrochemical systems.

The aim of this work is to study the conjunctional effect when integrating the catalyst (modified kaolin) into the electrochemical system and find out the optimal operating parameters in treating the dyes making wastewater.

\section{Experimental}

All chemicals used in this work were analytically pure reagents. Dyes used in this study were Acid Yellow 65 (AY) (FW=590.57) (CI 14170) and Acid Violet 5 (AV) $(\mathrm{FW}=678.63)$ (CI 18125), the structural formulae of which are shown in Table 1 . The simulated wastewater was made alkaline or acid by the addition of sodium hydroxide and sulphuric acid, respectively. 
Table 1. Structural formulae of the treated dyes.

Dye

Structural formula

Acid
Yellow

65

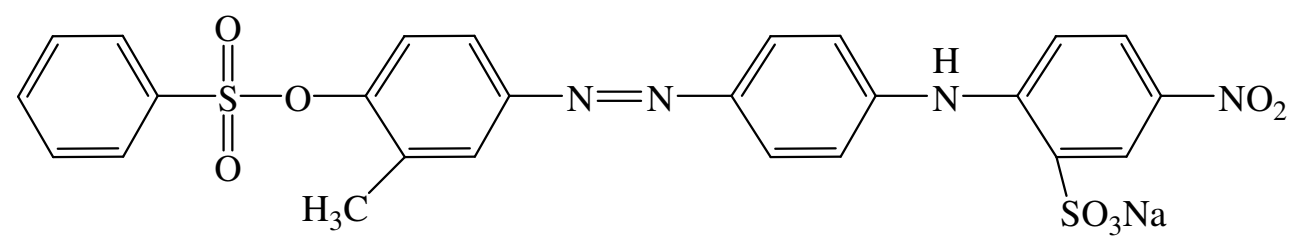

Acid Violet 5<smiles>CC(=O)Nc1ccc(N=Nc2c(S(N)(=O)=O)cc3cc(S(N)(=O)=O)cc(NS(=O)(=O)c4ccc(C)cc4)c3c2O)cc1</smiles>

The experiments were conducted in an undivided cell of $200 \mathrm{~mL}$ capacity under constant temperature. Electrodes were served by porous graphite. The anode and cathode were positioned vertically and parallel to each other with an inner gap of $1 \mathrm{~cm}$. The superficial surface of the working electrode $(3 \times 6 \mathrm{~cm})$ was $18 \mathrm{~cm}^{2}$. The cathode was positioned between two anodes. The modified kaolin catalyst was added into the system to form an oxidizing electrochemical reactor. The solution was constantly stirred (200 rpm) with a magnetic stirrer in order to maintain a uniform concentration of the electrolyte solution. The electric power was supplied with a regulated power supply (model GP 4303D, LG. Precision, Co. Ltd, Korea). The current and potential measurements were carried out using digital multimeter (Kyoritsu mode 1008, Japan).

All the experiments were carried out in duplicate and analysis of each parameter was done in triplicate for each run. The initial $\mathrm{pH}$ of the solution was measured using a Cole Pormer (model Microprocessor $\mathrm{pH} / \mathrm{mV} /{ }^{\circ} \mathrm{C}$ meter, USA). COD was chosen as a parameter in order to evaluate the process of oxidation and was determined according to standard methods for the examination of water and wastewater. The COD removal\% was calculated as follows:

$$
\mathrm{COD} \text { removal } \%=\left[1-\mathrm{COD} / \mathrm{COD}_{\mathrm{o}}\right] \times 100
$$

where $\mathrm{COD}_{\mathrm{o}}$ : $\mathrm{COD}$ value before treatment, and $\mathrm{COD}: \mathrm{COD}$ value after treatment.

The $\mathrm{Cu}_{2} \mathrm{O}-\mathrm{CoO}-\mathrm{PO}_{4}{ }^{3-}$ modified kaolin catalyst was prepared as follows [16]: adding $50 \mathrm{~g} \mathrm{Cu}\left(\mathrm{NO}_{3}\right)_{2}, 20 \mathrm{~g} \mathrm{Co}\left(\mathrm{NO}_{3}\right)_{2}$ and $50 \mathrm{~g} \mathrm{Na}_{3} \mathrm{PO}_{4}$ into $250 \mathrm{~mL}$ distilled water ( $\mathrm{pH} 7.1$ ); $10 \mathrm{~mL} \mathrm{H}_{3} \mathrm{PO}_{4}$ were added to dissolve nitrate salts of $\mathrm{Cu}$ and $\mathrm{Co}$, then the solution $\mathrm{pH}$ was adjusted with $\mathrm{NaOH}$ to a neutral condition. $200 \mathrm{~g}$ of kaolin powder which was used as support were impregnated into the solution 
with mechanical stirring in a water bath at $50{ }^{\circ} \mathrm{C}$ for 4 hours. After this, the solution was aged at room temperature for 48 hours and filtered, and washed and the filter was dried at $100{ }^{\circ} \mathrm{C}$ for 4 hours. To immobilize the metals, the prepared dried slurry was calcined at $600{ }^{\circ} \mathrm{C}$ in a muffle furnace.

\section{Results and discussions}

A series of experiments was carried out to investigate the effect of different operating conditions on the rate of electrochemical degradation of the investigated dyes.

\section{Synergetic effect}

In the presence of the catalyst (modified kaolin), organic pollutants can be degraded by electrolysis and removed by adsorption. To evaluate the feasibility of adding catalyst into the electrocatalysis process, the efficiencies of COD removal in (1) only modified kaolin, (2) electrocatalysis process and (3) their combined processes in the same reactor, were determined. The experiments were carried out under the following operating conditions: $100 \mathrm{mg} / \mathrm{L}$ initial dye concentration with corresponding initial COD of $200 \mathrm{mg} \mathrm{O}_{2} / \mathrm{L}$ for Acid Yellow dye and $250 \mathrm{mg} \mathrm{O}_{2} / \mathrm{L}$ for Acid Violet dye, current density of $50 \mathrm{~mA} / \mathrm{cm}^{2}$, pH of 3 , temperature of $25{ }^{\circ} \mathrm{C}$, electrolysis time of $50 \mathrm{~min}$., and the amount of modified kaolin added was $15 \mathrm{~g} / \mathrm{L}$. Effect of modified kaolin's adsorption was performed at the same conditions except the absence of current. Fig. 1 shows the COD removal percentage for the investigated dyes (AY,AV) in the above mentioned three processes. Such a combined process obtained a $99 \%$ COD removal for AY dye compared with 57\% and 32\% COD removal in catalyst adsorption process and electrochemical process, respectively. For AV dye these values were: $98 \%$, $55 \%$ and $31 \%$, respectively. However, the two processes (catalyst adsorption, electrocatalysis) were not environmentally equivalent, due to the accumulation of unconverted contaminants on the solid phase by adsorption. Moreover, the whole combined process is a mass transfer process and its COD removal rate may depend on the different operating conditions.

\section{Effect of current density}

Different current densities $\left(0-50 \mathrm{~mA} / \mathrm{cm}^{2}\right)$ were applied to investigate the electrocatalytic degradation of Acid Yellow and Acid Violet dyes in the presence of modified kaolin catalyst. The operating conditions were: $100 \mathrm{~g} / \mathrm{L}$ initial dye concentration, $\mathrm{pH}$ of 3 , temperature of $25^{\circ} \mathrm{C}$, electrolysis time of $50 \mathrm{~min}$., $15 \mathrm{~g} / \mathrm{L}$ modified kaolin catalyst. The COD removal\% of the two dyes increased with increasing the applied current density, as indicated from Fig. 2. The COD removal\% increases with increasing the current up to $35 \mathrm{~mA} / \mathrm{cm}^{2}$ for Acid Yellow dye and up to $40 \mathrm{~mA} / \mathrm{cm}^{2}$ for Acid Violet dye, at which complete removal occurred. 


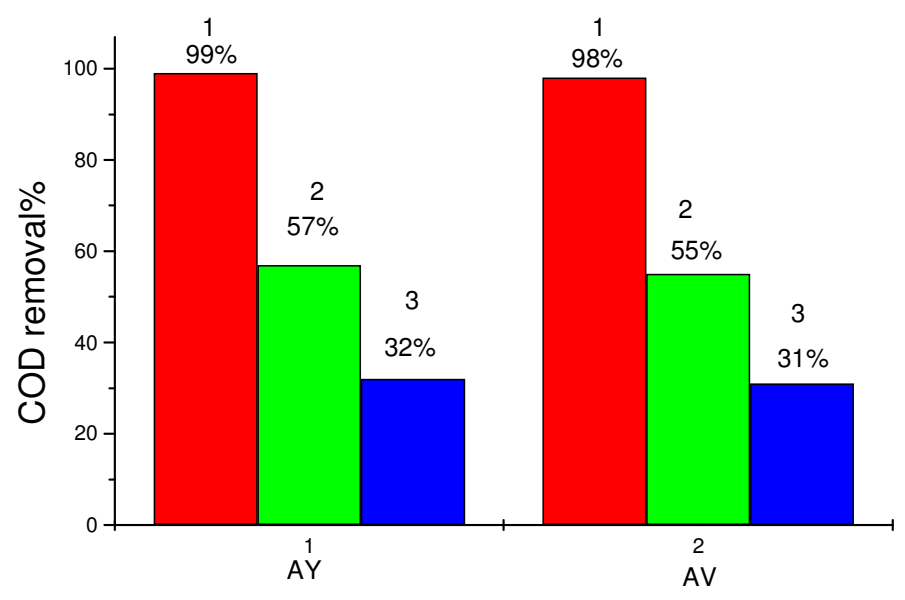

Figure 1. Synergetic effects on COD removal \% in: 1- the combined process, 2catalyst adsorption process, 3- electrochemical process for Acid Yellow (AY) and Acid Violet (AV) dyes.

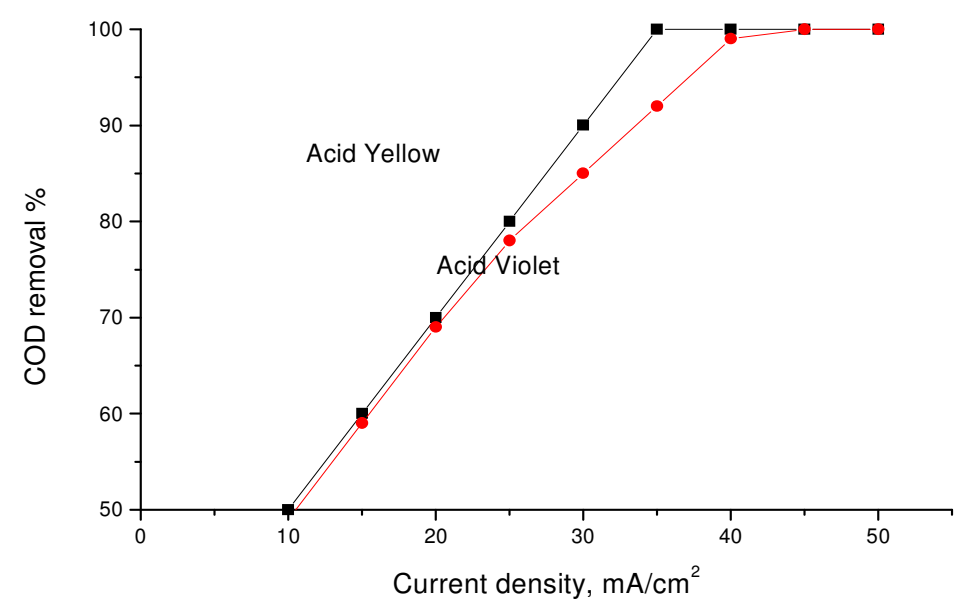

Figure 2. Effect of applied current density on COD removal \% for Acid Yellow and Acid Violet in the presence of modified kaolin catalyst.

\section{Effect of solution $\mathrm{pH}$}

The solution $\mathrm{pH}$ was varied from 1 to 12 in order to determine its effect on the electrocatalytic degradation of Acid Yellow and Acid Violet dyes in the presence of modified kaolin catalyst. Fig. 3 shows the variation of COD removal\% of the two dyes as a function of solution $\mathrm{pH}$. All the operating conditions for the treatment of the two dyes are similar, $100 \mathrm{mg} / \mathrm{L}$ initial dye concentration, 40 $\mathrm{mA} / \mathrm{cm}^{2}$ current density, temperature of $25{ }^{\circ} \mathrm{C}$, electrolysis time of $50 \mathrm{~min} ., 15$ $\mathrm{g} / \mathrm{L}$ modified kaolin catalyst. The plots of Fig. 3 indicated that the highest electrocatalytic activity was obtained in the acidic range of $\mathrm{pH}$. 


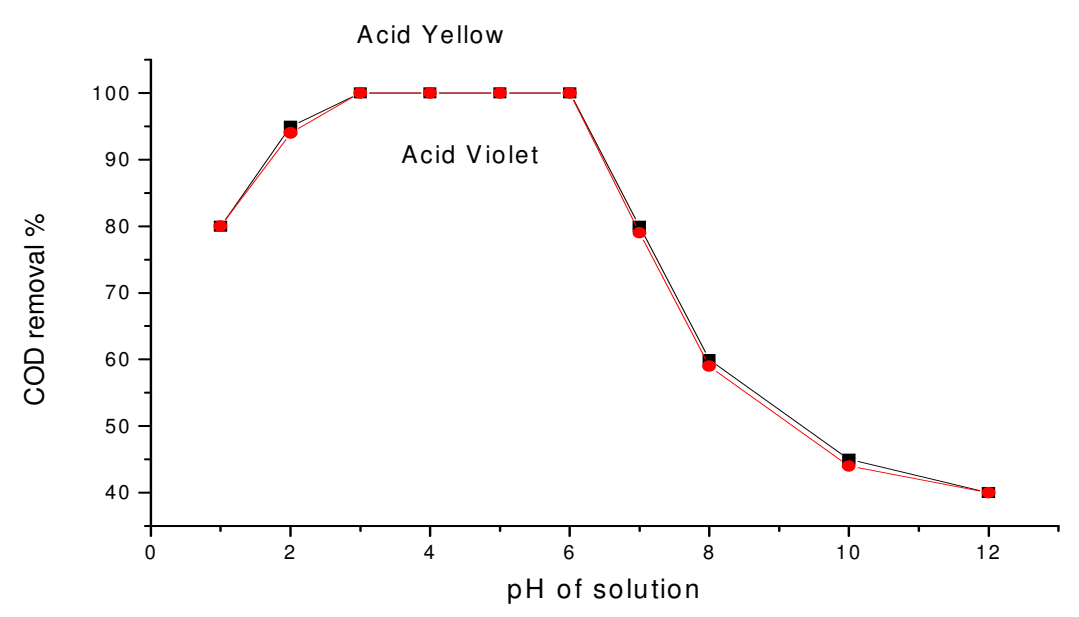

Figure 3. Effect of solution $\mathrm{pH}$ on the COD removal \% for Acid Yellow and Acid Violet dyes in the presence of modified kaolin catalyst.

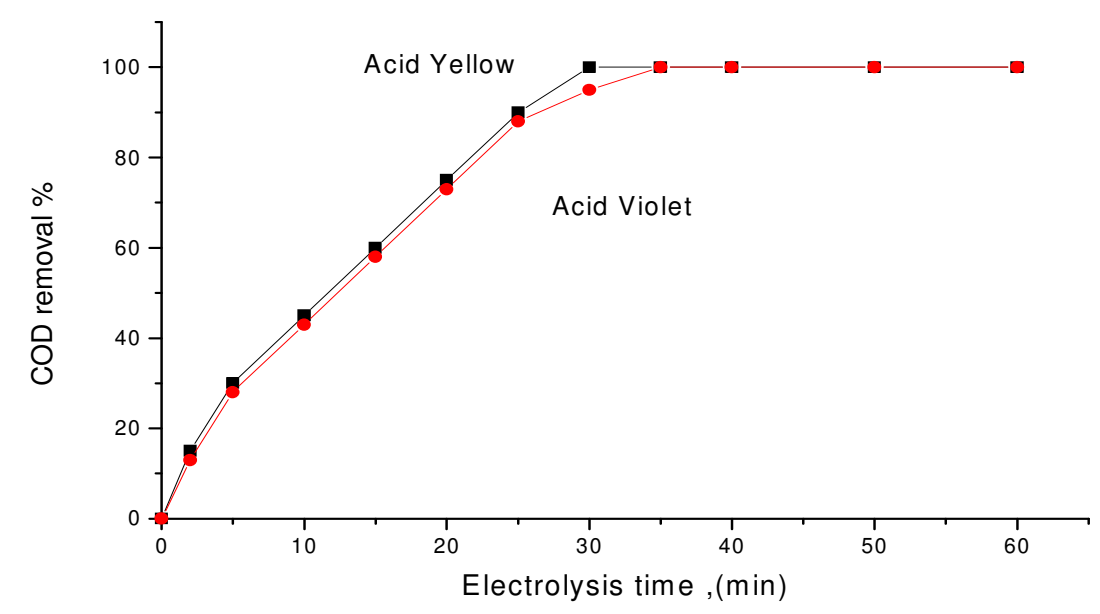

Figure 4. Removal $\%$ for Acid Yellow and Acid Violet as a function of time of electrolysis in the presence of modified kaolin catalyst.

\section{Effect of electrolysis time}

Investigation of the effect of electrolysis time on the combined electrocatalytic degradation process of Acid Yellow and Acid Violet dyes was carried out. The operating conditions were: $100 \mathrm{mg} / \mathrm{L}$ initial dye concentration, current density of $40 \mathrm{~mA} / \mathrm{cm}^{2}$, temperature of $25{ }^{\circ} \mathrm{C}, \mathrm{pH}$ of 3 and in presence of $15 \mathrm{~g} / \mathrm{L}$ modified kaolin catalyst. The plots of Fig.(4) indicated that the COD removal\% of both dyes increased with increasing electrolysis time. The maximum COD removal\% was obtained after 30 min. for Acid Yellow dye and 35 min. for Acid Violet dye. 


\section{Effect of the amount of modified kaolin catalyst}

In this investigation the operating conditions were: $100 \mathrm{mg} / \mathrm{L}$ initial dye concentration, $40 \mathrm{~mA} / \mathrm{cm}^{2}$ current density, $\mathrm{pH}$ of 3, $40 \mathrm{~min}$. electrolysis time, temperature of $25{ }^{\circ} \mathrm{C}$. The modified kaolin catalyst dose varied from 0 to $60 \mathrm{~g} / \mathrm{L}$. Fig. 5 shows the effect of catalyst dose on the COD removal\% of Acid Yellow and Acid Violet dyes. A general trend was for both dyes, an increase of the COD removal\% of dyes with increasing amount of catalyst up to $20 \mathrm{~g} / \mathrm{L}$, above which there was no additional effect of catalyst. In other words complete degradation of both dyes was achieved in the presence of $20 \mathrm{~g} / \mathrm{L}$ of catalyst.

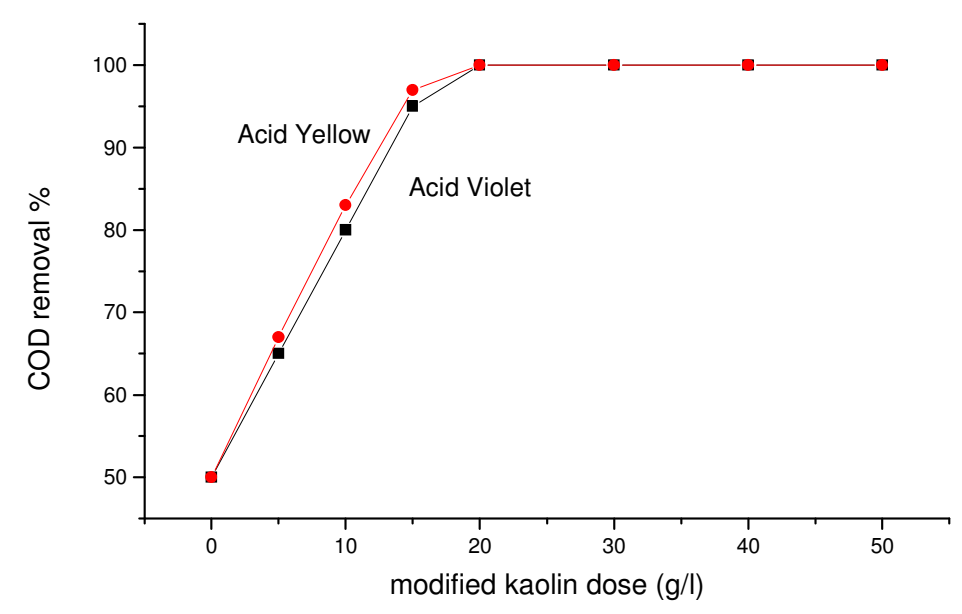

Figure 5. Effect of modified kaolin dose on COD removal\% for Acid Yellow and Acid Violet dyes.

\section{Effect of initial dye dosage}

Fig. 6 displays the effect of different dye concentrations up to $400 \mathrm{mg} / \mathrm{L}$ on the COD removal\% of Acid Yellow and Acid Violet dyes. The operating conditions were: $40 \mathrm{~mA} / \mathrm{cm}^{2}$ current density, $\mathrm{pH}$ of 3, electrolysis time of 40 minutes and temperature of $25{ }^{\circ} \mathrm{C}$. Total removal of both dyes can be achieved in the presence of initial dye load up to $200 \mathrm{mg} / \mathrm{L}$. However, increasing the dye concentration above this level resulted in a decrease in the electrocatalytic rate of degradation of both dyes. Although the COD removal\% of both dyes decreased with increasing the initial dye dose, good removal efficiencies were achieved at a relatively high dye load, as indicated from Fig. 6. For example, the COD removal\% of the dyes at $400 \mathrm{mg} / \mathrm{L}$ initial concentration was $78 \%$ for Acid Yellow and $76 \%$ for Acid Violet. 


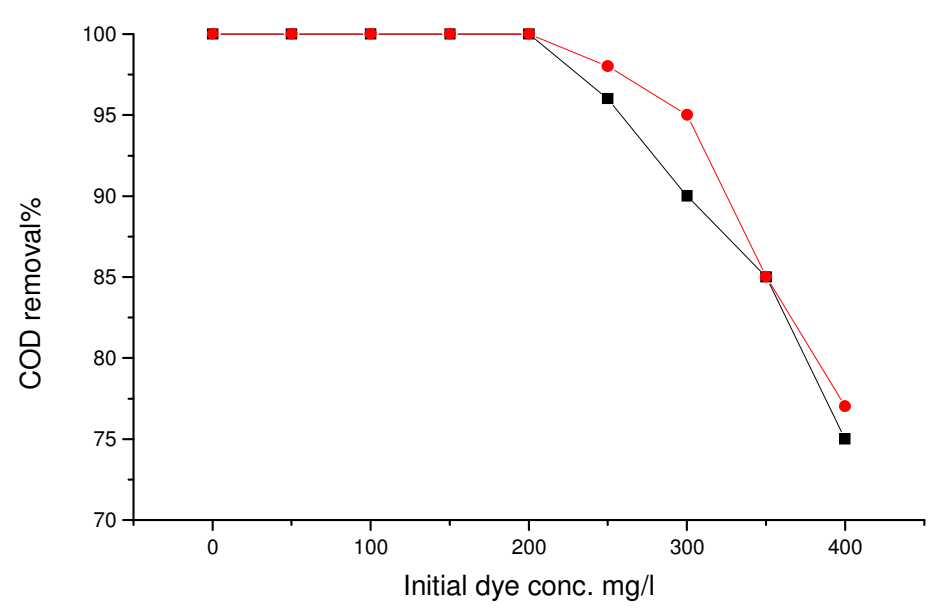

Figure 6. Effect of initial dye load on COD removal \% for Acid Yellow and Acid Violet in the presence of modified kaolin catalyst.

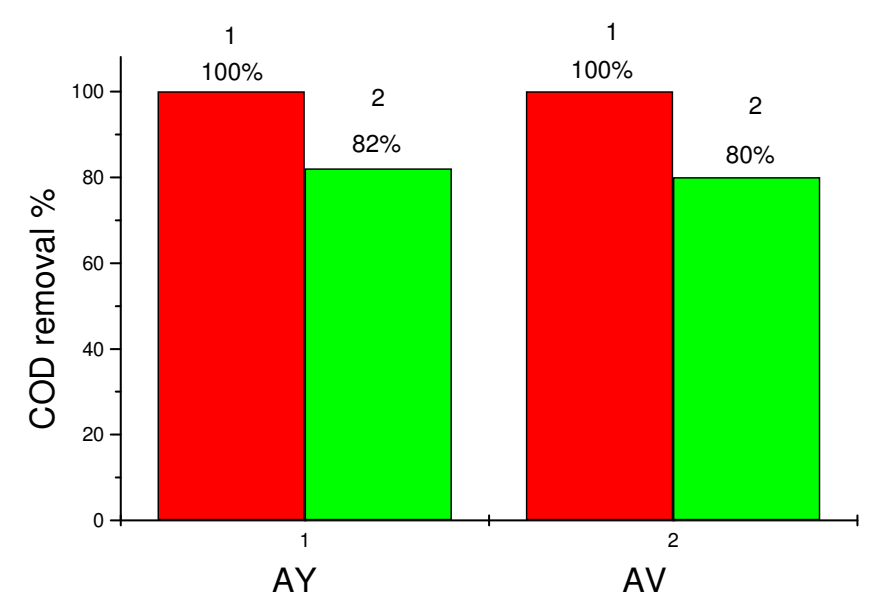

Figure 7. Comparison of electro $\mathrm{Co}-\mathrm{Cu}$-modified kaolin heterogeneous system (1) and electro Co-Cu homogeneous system (2) on COD removal \% for Acid Yellow (AY) and Acid Violet (AV).

\section{Comparison with homogeneous $\mathrm{Co}$ and $\mathrm{Cu}$ combined system}

To evaluate the effect of $\mathrm{Cu}_{2} \mathrm{O}-\mathrm{CoO}-\mathrm{PO}_{4}{ }^{3-}$ modified kaolin in an electrochemical system concerning the ability to degrade pollutants, the homogeneous electro$\mathrm{Co}-\mathrm{Cu}$ combined system was applied. $15 \mathrm{~g} / \mathrm{L} \mathrm{CoSO}_{4}$ or $\mathrm{CuSO}_{4}$ were added into the solution instead of modified kaolin. The operating conditions were: $40 \mathrm{~mA}$ $/ \mathrm{cm}^{2}, \mathrm{pH}$ of 3 , temperature of $25{ }^{\circ} \mathrm{C}$, and initial dye concentration of $100 \mathrm{mg} / \mathrm{L}$. Fig. 7 shows the values of COD removal \% for the two dyes in the two systems (homogeneous and heterogeneous combined systems). It is clear from this figure that, when treating pollutants in aqueous phase, the electro $\mathrm{Co}-\mathrm{Cu}$ modified kaolin heterogeneous system is more advantageous than the electro $\mathrm{Co}-\mathrm{Cu}$ homogeneous system. 
In this paper, the combined electrocatalytic oxidation of dye making wastewater in the presence of $\mathrm{Cu}_{2} \mathrm{O}-\mathrm{CoO}-\mathrm{PO}_{4}{ }^{3-}$ modified kaolin was investigated. Two processes are involved in the whole degradation process: i- adsorption of dye on the catalyst and ii- electrocatalytic oxidation process. By adsorption process, pollutants can be immediately adsorbed on the catalyst due to its high BET surface and porous structure. By combined electrochemical oxidation process, strong oxidants produced through decomposition of electro generated $\mathrm{H}_{2} \mathrm{O}_{2}(\mathrm{HO} *$ and $\mathrm{HO}_{2}{ }^{*}$ radicals) can destruct organic pollutants and convert them into $\mathrm{CO}_{2}$ and $\mathrm{H}_{2} \mathrm{O}$. Near carbon anode, the evolution of $\mathrm{O}_{2}$ with high yield can immediately be reduced on the porous graphite cathode to form $\mathrm{H}_{2} \mathrm{O}_{2}$ :

$$
\begin{array}{r}
2 \mathrm{H}_{2} \mathrm{O} \rightarrow \mathrm{O}_{2}+4 \mathrm{H}^{+}+4 \mathrm{e} \\
\mathrm{O}_{2}+2 \mathrm{H}^{+}+2 \mathrm{e} \rightarrow \quad \mathrm{H}_{2} \mathrm{O}_{2}
\end{array}
$$

In the presence of transition metals modified kaolin, oxidant formation is as follows:

$$
\begin{gathered}
\mathrm{H}_{2} \mathrm{O}_{2}+\mathrm{Cu}^{+} \rightarrow \mathrm{Cu}^{++}+\mathrm{HO}^{*}+\mathrm{OH}^{-} \\
\mathrm{H}_{2} \mathrm{O}_{2}+\mathrm{Co}^{++} \rightarrow \mathrm{Co}^{+++}+\mathrm{HO}^{*}+\mathrm{OH}^{-} \\
\mathrm{H}_{2} \mathrm{O}_{2}+\mathrm{Cu}^{++} \rightarrow \mathrm{Cu}^{+}+\mathrm{HOO}^{*}+\mathrm{H}^{+} \\
\mathrm{H}_{2} \mathrm{O}_{2}+\mathrm{Co}^{+++} \rightarrow \mathrm{Co}^{++}+\mathrm{HOO}^{*}+\mathrm{H}^{+}
\end{gathered}
$$

This process is similar to the electro-Fenton process. However in the $\mathrm{Fe}^{2+}$ homogenous aqueous phase, electro generated $\mathrm{H}_{2} \mathrm{O}_{2}$ can diffuse to the anode forming $\mathrm{O}_{2}$ :

$$
\mathrm{H}_{2} \mathrm{O}_{2} \rightarrow \mathrm{O}_{2}+2 \mathrm{H}^{+}+2 \mathrm{e}
$$

The $\mathrm{pH}$ of the solution plays a very important role in influencing the electrochemical process, such as concentration of electro generated $\mathrm{H}_{2} \mathrm{O}_{2}$ (equation 3), oxidant $\mathrm{HO}^{*}$ radicals (equations 4,5) and the structure of the organic compounds and their stabilities. The better effectiveness at $\mathrm{pH}$ 3-5 agrees with the fact that the maximum rate for $\mathrm{HO}^{*}$ generation should be in acid solutions, while the diffused oxygen may get electrons easily in this $\mathrm{pH}$ region. In alkaline solution, hydroxide, bicarbonate and carbonate can scavenge hydroxyl radicals [17]:

$$
\mathrm{HO}^{*}+\mathrm{OH}^{-} \rightarrow \mathrm{H}_{2} \mathrm{O}+\mathrm{O}^{*-}
$$

which influences the oxidizing property of the free radical to degrade the organic compounds and this result was similar to the previously reported [12,16], where 
the catalyst displays higher catalytic activity in the acid and moderate acid solutions.

It was shown that COD removal\% increased with the increase of the amount of the catalyst up to $20 \mathrm{~g} / \mathrm{L}$, at higher amounts of catalyst the variation of COD removal\% becomes unapparent. This means that, when the catalyst reaches a certain amount, it will reach equilibrium with electro generated $\mathrm{H}_{2} \mathrm{O}_{2}$, so the generation of $\mathrm{HO}^{*}$ was mainly determined by the concentration of $\mathrm{H}_{2} \mathrm{O}_{2}$. Moreover, because the whole degradation process is mass transfer controlled, its COD removal\% may depend on stirring speed, particle size and also solution conditions. When the catalyst reaches a certain amount, the COD removal\% may further be influenced by other factors.

The multi-transition metals kaolin gains more advantage than $\mathrm{Co}-\mathrm{Cu}$ homogeneous catalyzed electrochemical when treating pollutants in aqueous phase, probably due to its ability to condense pollutants and electro generated $\mathrm{H}_{2} \mathrm{O}_{2}$ onto its big surface and making the reaction more easily to occur. Moreover, because electro $\mathrm{Co}-\mathrm{Cu}$ modified kaolin system is heterogeneous, the adsorbed multi-metal compounds were stable and friendly to the environmental pollution [16].

\section{Conclusion}

The combined electrocatalysis of dyes wastewater assisted with $\mathrm{Cu}_{2} \mathrm{O}-\mathrm{CoO}-\mathrm{PO}_{4}{ }^{3-}$ modified kaolin catalyst was performed in the single undivided cell. The catalyst was prepared as mentioned in the literature. Optimal operating conditions such as initial $\mathrm{pH}$, current density, electrolysis time and amount of modified kaolin catalyst were determined. It was found that when the initial $\mathrm{pH}$ was 3 , current density of $40 \mathrm{~mA} / \mathrm{cm}^{2}$, time of electrolysis 40 minutes and modified kaolin catalyst of $15 \mathrm{~g} / \mathrm{L}$, the COD removal\% of the investigated dyes can reach $100 \%$. The removal of dyes from the wastewater may be attributed to strong oxidant that is produced from the synergetic effect between modified kaolin and electrochemical system.

\section{References}

1. S. Defazio, A.T. Lemley, J. Environ. Sci. Health Pt. A 34 (1999) 217.

2. X. Chen, Z. Shen, X. Zhu, Y. Fan, W. Wang, Water SA 31 (2005) 127.

3. S. Lj. Gojkovic, T.R. Durovic, Electrochim. Acta 48 (2003) 3607.

4. P. Coňizares, C. Sâez, J. Lobato, M.A. Rodrigo, Electrochim. Acta 49 (2004) 4641.

5. V.M. Jovanovic, S. Terzic, A.V. Tripkovic, K. Dj. Popovic, J.D. Lovic, Electrochem. Commun. 6 (2004) 1254.

6. P. Sonthalia, E. McGraw, Y. Show, G.M. Swain, Anal. Chim. Acta 522 (2004) 35.

7. J. Yang, J. Jia, J. Liao, Y Wang, Water Res. 38 (2004) 4353.

8. K. Rajeshwar, J.G. Ibanez, G.M. Swain, J. Appl. Electrochem. 24 (1994) 1077. 
9. A.M. Polcaro, S. Palmas, Electrochemical oxidation of chlorophenols, Ind. Eng. Chem. Res. 36 (1997) 1791.

10. A.G. Vlyssides, M. Loizidous, P.K. Karlis, A.A. Zorpas, D. Papaioannou, J. Hazard Mater. B 70 (1999) 41.

11. L. Greet, P. Jan, V. Mare, P. Luc, V. Willy, Electrochem. Acta 4 (2003) 1656.

12. M. Zh. Ma, B. Wang, J. Hazard Mater. 132 (2006) 237.

13. L. Gu, B. Wang, M.Z. Ma, J. Hazard Mater. 137 (2006) 842.

14. Y.L. Wei, S.Y. Chiu, H.N. Tsai, Y.W. Yang, J.F. Lee, Environ. Sci. Technol. 36 (2002) 4633.

15. J. Zhao, B. Wang, H. Zh. Ma, J.T. Zhang, Ind. Eng. Chem. Res. 45 (2006) 4530.

16. B. Wang, L. Gu, H. Ma, J. Hazard Mater. 143 (2007) 198.

17. K.B. Suresh, T. James, P. Jaidev, E. Karl, B.A. Depak, C.G. Stephen, Ind. Eng. Chem. Res. 45 (2006) 1221. 